\title{
Assessing Students' Minds: Developing Critical Thinking or Fitting into Procrustean Bed
}

\author{
Ulker Shafiyeva \\ PhD, Head of the Department of Languages at the Academy of Public \\ Administration under the President of Azerbaijan and Adjunct Writing, \\ Instructor at ADA University
}

\section{Abstract}

Standardized tests have been applied as student knowledge assessment in many countries, including Azerbaijan. However, studies have shown that standardized tests are not an effective way of measuring students' knowledge because they limit students' creativity and prevent instructors from applying individual teaching methods due to the pressure of passing the tests. The tests do not consider students with different learning abilities and treat them equally, which may not favor some students. Also, teachers are pressured to ensure their students pass the tests, leading to an excessive focus on the topics likely to be set rather than the whole curriculum. The study recommends implementing different assessment methods with no ranking to ensure that students do not memorize for passing tests, eliminate competition, and promote equality in the education sector. The assessment methods should allow students to debate, compare and analyze ideas through critical thinking, inquiring, and understanding for applying the learned knowledge into real life. Thus, the importance of an inquiry-based curriculum and assessment is stressed.

Keywords: standardized tests, creativity, individualism, critical thinking, multiple assessment methods, Azerbaijan, equality, students' knowledge, inquiry

\section{Introduction}

What is knowledge? What kind of knowledge must be assessed? These two closely interlinked questions can set the base for the educational philosophy we need at schools. Today, knowledge assessment heavily relies on standardized testing. However, at the same time, the innovations in education and technology have made it essential to create more modern knowledge assessment tools.

Students' knowledge evaluation has gone through different stages of changes in different societies. It is widely accepted that educators need a tool to evaluate students' academic performance and knowledge level. Traditionally students 
demonstrate and certify their knowledge by answering questions on past material. What became different in recent years is that the arrival of the knowledge economy and new teaching philosophy, which emphasizes critical thinking, has created more precise knowledge evaluation. In addition, the widespread use of standardized testing has generated questions about its accuracy and efficacy for the demands of modern teaching methods and the job market.

The question of what kind of tests can best evaluate students' knowledge is still under discussion. Unlike the past, when the source of knowledge was teachers and libraries, today, the internet has become a significant source of easily accessible knowledge. As a result, it significantly impacted how knowledge must be delivered, learned, and assessed.

Besides the inquiry into the problem from the general perspective, this paper reflects on the dilemma of standardized testing in Azerbaijan.

\section{Literature Review}

The global economy is gradually changing, and every country must emphasize education systems that would encourage innovation and knowledge towards the globalized economy. According to Caroll (2013), some students may perform well in standardized tests and move into high schools; however, they struggle in basic skills and knowledge. Critical thinking is essential in education because it enables students to apply their learned skills to real-life problems. Standardized testing has been applied in various learning institutions as a method to measure student's knowledge. However, Albino (2008) states that standardized testing may not be the most effective assessment strategy since assessments are not merely auditing the student's performance but improving the student's education. Therefore, testing assessments should aim at helping the education stakeholders and the government make informed decisions that would assist in improving the education sector in the country. Caroll (2013) adds that critical thinking is based on students' ability to reevaluate their thoughts, intending to improve them. Therefore, standardized testing may not provide the students with an opportunity to reevaluate their thoughts and skills. Chomsky\& Robichaud (2014) argues that standardized testing is politically made to diminish teachers' and students' creativity so that to forge uniformity and control. The study further argues that standardized tests present an idea of privatized power to prevent the majority from reaching the top of the social, economic, and political class.

A study by Shively, Stith, \& Rubenstein (2018), which aims to evaluate the benefits of measuring design process creativity and critical thinking in gifted education, states that in standardized assessment, if students were to develop cars, scores would be given based on the speed of the car, distance covered and how it looks. However, these aspects are not adequate to measure the students' skills and knowledge; therefore, various assessment tools should be employed to measure skills, knowledge, and 
critical thinking. Similarly, Smith \& Szymanski (2013) states high stakes and consequences concerning standardized tests. Most education institutions use standardized tests to promote the student to the next grade, to be admitted to a college, or to graduate from high school. For example, several schools have applied standardized testing when selecting students for honors programs in Azerbaijan. A study by Abizada \& Mirzaliyeva (2019) notes that Azerbaijan's learning institutions use students' first-year perfomance, the honors-program selection test, and the university centralized admission tests to predict student's academic success in their program. However, it states that these criteria may only be effective in some programs; therefore, there should be different assessment methods depending on the study program. Novinger \& Compton-Lilly (2005) argues that standardized tests are unfair because "all kids can't achieve at the same level" (p.195); therefore, standardized testing leads to demeaning of some students, and it would be better if students were given basic tests and only on things they would need to apply in their daily lives.

While these tests make students and teachers accountable, the stakes in the results have been put so high that some students become depressed and demotivated to study (Smith \& Szymanski, 2013). A study by Phi Delta Kappa (2015) states that 64\% of American parents believe the schools have adopted too much standardized testing, ignoring other aspects of students' knowledge assessment. A study by Shukakidze (2013) to understand how school, family, and student factors impact the students' achievement in Azerbaijan and Estonia noted that standardized testing in Azerbaijan might be unfair to assess students' knowledge. The study used 4600 Azerbaijan students to answer how students' background, family-related issues, and schoolrelated issues affect their scores in standardized testing. The study concluded that several variables impact oral communication, reading, and writing assessment method because it ignores individualism and social variables that influence students' test outcomes.

Phi Delta Kappa (2015) further states that most parents believe American instructors have deviated from giving students the knowledge to "teaching the tests" due to the high pressure of achieving the required minimum. The pressure originates from the public, parents, principals, and education managers. This pressure has resulted in skewed teaching systems aiming to pass the standardized tests even though there are minimum studies on the connection between creative thinking and standardized tests. Smith \& Szymanski (2013) states that the level of creativity in America has been diminishing in the last 50 years even though I.Q. test scores have risen since 1990. Most teachers have been focusing on education areas included in the standardized tests, ignoring areas requiring creativity and critical thinking.

Similarly, Berliner (2009) states that a third of North Carolina instructors spent more than $60 \%$ of teaching hours preparing students for state standardized tests, ignoring most of the teaching materials they deem may not be tested. This shows that 
standardized testing harms a country's education system, and there should be alternative ways of evaluating student's knowledge. A study by Moon et al. (2007) to understand the impact of standardized testing on teachers, students, and schools found that students and teachers feel pressured by such tests due to high stakes placed in them. This pressure is the motivation that instructors use to design the curriculum areas that they will teach. Such tests are disadvantaged because schools that underperform in the standardized tests are unlikely to attract new students, and the teachers may be viewed as underworking. Talented and gifted students may fail to exploit their full potential due to the pressure of passing the standardized tests. The Azerbaijan study by Eminli (2019) states that multiple-choice tests dominate Azerbaijan education assessments. They are inappropriate for measuring students' knowledge since teaching should focus on academic writing at the secondary school level instead of multiple choices that can limit student's thinking.

Further, Briggs (2013) states that standardized testing of students harms learning in several ways. Briggs argues that standardized testing is misled and misused because schools and districts in America have been involved in test cheating to get higher grades, especially by giving students tests before the stipulated time or students caught changing their answers in states like Atlanta, Texas, and Washington. The standardized tests also kill knowledge because students may have knowledge but fail to use it. Jorgenson (2012) describes standardized tests as "Sit, Get, Spit, Forget," where students do not demonstrate their skills in explaining, researching, public speaking, and reflecting, among others. University admission in many countries is based on standardized tests but focuses little on creativity and critical thinking (McCarthy\& Blake, S 2017).

In addition, most schools use summative assessment methods, where students are tested at the end of the semester to understand whether the students have met the study objectives (Gardner, 2012). However, Briggs (2013) argues that standardized tests have defined students, equating them to their scores. As a result, the students are influenced to compare themselves with their peers and may put some of the students at a disadvantage; therefore, even though standard tests provide a consistent measurement method, the end product of the tests is not beneficial to all students. Similarly, Moon et al. (2007) argue that some students equate the results of the tests with their self-worth, making those who underperform have low self-esteem and feel demotivated to learn. Orfield (2004) adds that a study at Harvard University found that standardized tests significantly contribute to student dropout. Students at the $10 \%$ bottom of the rating scale had a $33 \%$ possibility of dropping out of college. They are affected even in their social life. Britanica (2020) adds that standardized tests have been used to create a bureaucracy in China, where those who can pass the tests are admitted to the top social class while those who fail to meet the required marks are ignored. For example, Spann and Kaufman (2015) state that in 2014, Peking, an elite university, admitted only $0.02 \%$ of students from Shadong 657,000 high school graduates, meaning that elite universities preserve positions for students coming 
from the capital than in rural areas. This argument is similar to Briggs's claim that more prominent companies like Google and Amazon look at the school test results before skills when looking for potential employers. Therefore, the impacts of standardized tests go beyond school.

A standardized testing system ignores students as individuals and treats them as a group despite their unique abilities and limitations. Altwerger et al. (2002) state that teachers have abandoned meaning-centered content in favor of commercial instructional schemes that only provide measurable reading skills with quantitative assessment, ignoring the quality of knowledge that the students may have acquired. Students learn differently; learning is relative, and teachers may apply different teaching methods (Taylor, 2021). Therefore, standardized tests may not be helpful in defining learning, ignoring slow learners and those abled differently. Also, Taylor argues that each different setting may call for different modes of teaching, and using standardized tests to evaluate teachers is unfair to both the teacher and students. Thus, instructors would be effective in their testing if they considered each student's background and learning mode to ensure they achieve the study's objectives. Briggs (2013) states that under pressure to perform in the standardized tests, schools ignore teaching areas that are not tested even though they may be part of the curriculum, especially on co-curricular activities. This trend limits the quantity and quality of education that students are given.

The purpose of this study was to test the hypothesis that standardized testing does not promote the creativity and individuality of the students. Thus, there are high stakes in these tests. The study also identifies the impacts of standardized tests on students, schools, and teachers. Recommendations are provided manifest that assessment methods implemented in the future will consider each student individually. The objectives will improve students' skills, enhance their creativity, and develop critical thinking and knowledge that may be useful even after school.

\section{Objectives of the study}

To identify the harmful effects of standardized testing on students and teachers.

To identify the impact of standardized testing on students' creativity and individuality.

To provide recommendations on potentially fair assessments methods

\section{Methodology}

To demonstrate that standardized tests do not promote critical thinking and do not consider individual abilities and students' individual needs, the study relied on secondary data where it employed evaluation of peer-reviewed journals, a systematic online search using keywords: standardized testing in Azerbaijan, negative effects of standardized testing in schools, effects of standardized testing in the United States, most effective students' assessment strategies, types of students tests, evaluation in 
education, the importance of tests in school, tests outcomes, tests, and academic success, standardized testing does not promote the creativity and individuality of the students, meaning of student creativity and individualism, among others.

The databases that have been used include Google Scholar, JSTOR, ProQuest, Azerbaijan government education websites, and PubMed. In addition, the researcher employed a desk survey (2) and document analysis (2). A total of 20 publications were thoroughly reviewed to understand their concepts of tests and education research, focusing on the effects of standardized testing on students, teachers, schools, and the primary motive behind standardized testing. The elimination strategy was applied using documents based on their perceptiveness, credibility, and authenticity. The research questions were:

1. What are the harms of standardized testing on students and teachers?

2. What are the potential alternatives of assessments that can promote fairness?

3. How can the education system promote student's creativity and individuality?

4. How effective are alternative student assessment methods

\section{Results}

From the qualitative and quantitative data analyzed from various studies, the majority agree that standardized tests do not promote students' critical thinking, creativity, and individualism. McCarthy \& Blake (2017) used a standardized test on 11 students and concluded that age played a significant role in student's results and creativity, where younger students were more creative than adults. The study also shows that students who score higher in the tests have a low capturing ability of concepts. Therefore, using standardized tests for students may limit their creativity, especially if they have not captured concepts. Similar, low capturing skills show that standardized tests are an ineffective way of measuring student's knowledge since some students may have high memory skills. Still, after the tests, they forget the concepts, leading to a wrong interpretation of the results. PISA (2021) argues that creative thinking is an essential part of the education system because it gives students the will and the need to change the world positively. Creative thinking helps students adapt to the changes of the world. However, these may not be measured in standardized testing, where students are given specific questions with multiple choices. Also, the studies argue that education should motivate students to show their creativity in answering questions and solving problems. However, the standardized tests force students to follow specific directions, limiting their ability to express their subject knowledge.

Because of stated rules that students and teachers have to follow in standardized testing, they cage students and teachers to show their creativity in thinking, expression, and problem-solving. Data by Nusche (2013) states that it is challenging 
to find a neutral and inclusive assessment method; therefore, teachers should implement multiple assessment strategies that promote fairness and promote students' creativity. The use of multiple assessments methods helps students who are not favored by standardized test methods to express their knowledge and skills differently. Nusche (2013) found that in Organisation for Economic Co-operation and Development (OECD) countries, $36 \%$ of the primary school principals are likely to admit students based on their standardized test results, while $18 \%$ of the principals are likely to transfer students showing low results in the standardized test. This data shows that standardized data leads to discrimination, where test results are used as the only tool to evaluate a student's potential. In addition, there are schools where students are grouped based on their abilities in particular subjects, 55\% in OECD countries (Nuesche 2013). In addition, the study has noted that standardized tests make most students be focused on good grades than the concepts of the study. Some students memorize a few facts before the tests, and after completing the test, the information is quickly forgotten (Jorgenson, 2012). Jorgenson shows that standardized tests ignore the fact that students have different learning styles. The tests do ignore public speaking creative skills. Children have no room to elaborate, explain, and debate, especially in countries where tests have multiple choices, like in Azerbaijan.

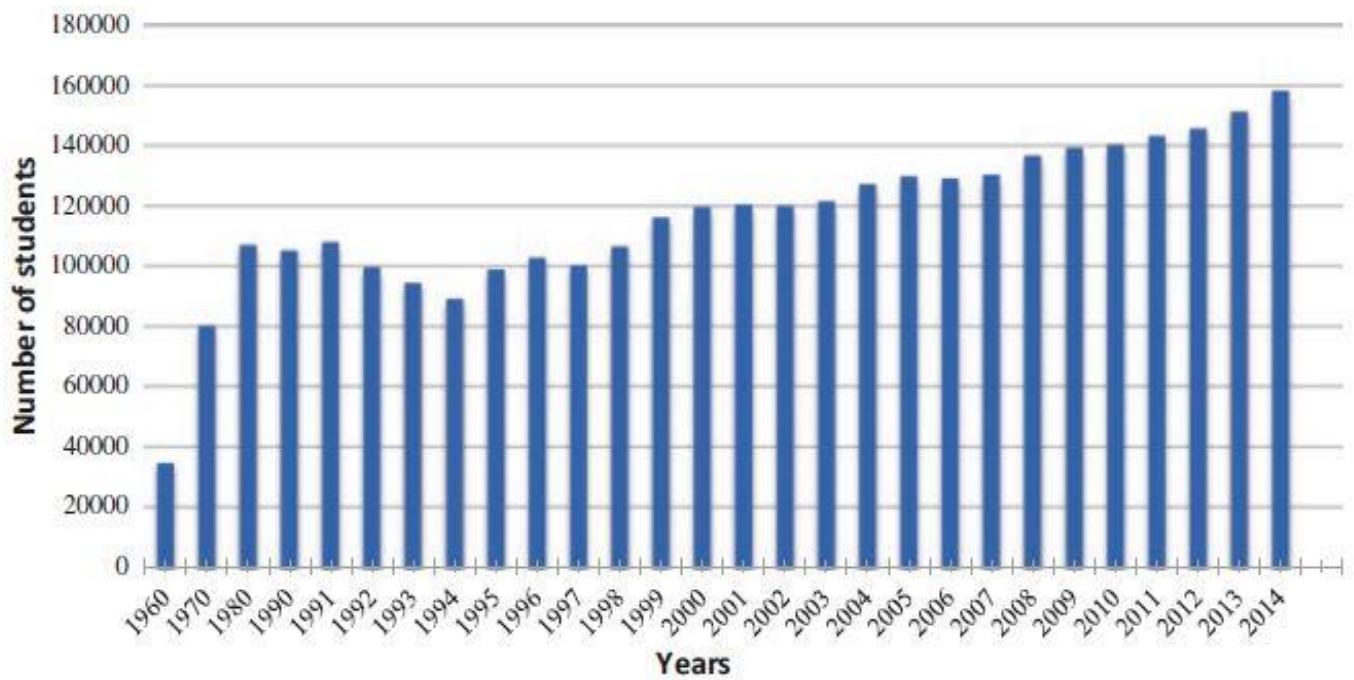

From the above statistics, it is evident that there is a significant increase in the number of students in institutions for higher learning. However, there have been debates in Azerbaijan on efficiency, harm, and effectiveness of standardized tests. There is little room for creativity and individualistic learning for students.

The analyzed studies show that standardized testing has made education a competition rather than a learning activity. In Singapore, students are subject-based 
grouped using the standardized test results, which is further used to determine whether they will join a college, university, or technical institute. The trend of a standardized test is common in many countries, including the United States, China, South Korea, Azerbaijan, and the United Kingdom, among others. Instead of thinking creatively and showing their knowledgeability, some students have resorted to cheating due to the pressure of passing the tests, making them unknowledgeable to be regarded as the best students when their results are not a reflection of their knowledge. Also, standardized tests make teachers treat students uniformly instead of assisting them individually, denying some students an opportunity to learn in their way.

Further, students may feel demoralized and have low self-esteem if they do not pass the standardized tests. This means that the tests ignore the student's individuality aspect, and assisting the slow learners may challenge some teachers. Finally, data shows that standardized tests deny the students an opportunity to participate in the curriculum development since the teacher aims to ensure that their students pass the tests, limiting their creativity and individuality in learning.

\section{Discussion}

Procrustean bed or fitting all students into one standard assessment tool is what one might define today's knowledge assessment. The origin of standardized testing goes back to the Chinese Han dynasty, employed to recruit staff for the state bureaucracy. Later it was adjusted to the needs of education and adopted first in Europe in the early $19^{\text {th }}$ century and later in the U.S. (Britannica, 2020)

Today employment of standardized tests has become an educational pandemic. In the world of speedy innovations, the approach to knowledge assessment has not significantly changed since then. The definition of literacy has evolved to meet the needs of society. Literacy was once defined as the ability to read, count, and write. In the previous century, when public education became a widespread institution in many states, education was characterized as a tool for adequate work skills and a medium for receiving information about political and social ideals. Nowadays, literacy is linked to the ability to perform specific tasks related to certain industries and a more sophisticated understanding of the political, economic, social, and cultural environment.

Therefore, tests are also changing - they are becoming more unified, complex, and sophisticated but not necessarily creative. Standardized tests cannot measure students' creativeness because, in preparing students for the test, the idea of individuality and uniqueness of each student is lost. Teachers' loss of freedom in the learning process hinders the ability to inspire students to develop their abilities individually and cultivate critical values. Moreover, teachers must devote much of their instructional time to preparing students for standardized tests rather than promoting creative, innovative, and critical thinking. 
The problem of standardized testing is multifaceted and can be examined through different perspectives depending on what we consider a challenge of this type of assessment and what these tests are applied for. Whether they are applied for obtaining professional diplomas or applied at educational institutions to test students' literacy, it is not arguable that we need some standard knowledge. The problem is how we teach and assess that knowledge.

Teaching students to fit into the standard knowledge assessment box without considering their individual needs and suppressing critical views also undermines the values of democracy. Children explore the world through touching, sensing, and asking multiple questions. That is how they learn and develop. It has to be understood that an adult's best way of learning still stays the same - through inquiring and applying the knowledge. Inquiry is a part of critical skill, which brings progress.

Altwerger and Strauss (2002) stress that big corporations are behind the promotion of standardized tests. Their interests go beyond the profit-making from test textbooks and testing industries. It also goes beyond interest to recruit skillful workers with demanded knowledge. Big corporations have interests in establishing a social order, which serves their benefit.

Novinger and Compton-Lilly (2005) illustrate through many stories told by parents that standard curricula harm children's ability to advance, reduces diversity, and deny differences. Instead, it promotes intellectual compliance and textbook industries, "serve[s] particular interests while silencing competing voices" (p.198). Novinger and Compton-Lilly further argue,

Too many schools are fixated on passing tests. Thousands of teachers are currently constrained by the discourses that position them as testers and technicians rather than as thoughtful individuals who work alongside parents for children (p.198)

Rees (2001) believes that forcing instructors to address content measured in standardized tests and avoid more analytical material hinders learning. Test preparation mania, which swept the American schools and is spreading further across the globe, endangers our diversity. Tests cannot measure critical thinking and truthfully evaluate students' knowledge.

Moreover, sometimes guessing and cramming can allow students to pass tests without deep knowledge of the subject. Special training actually can help pass the test. Chomsky and Robichaud (2014) argue that:

Teaching for tests instead of cultivating one's intrinsic interest is just inconceivable from a humanistic point of view, considering that students are being trained instead of encouraged creatively and individually. By doing so, with standardized practices, it tends to undermine any likelihood of the child wanting to learn or gain the capacities to proceed on his own (p. 5) 
There are some other arguments about the efficacy of standardized testing. The test is a measurement taken at a particular time. A student taking the test can be sick, hungry, nervous, frustrated, or disturbed by some events in their personal life. The question evolves around evaluating students' past learning experience appropriateness within a 2-3 hours period.

The problem of standardized testing and curriculum should also be approached from a political viewpoint. Teachers lose the freedom to implement the teaching material, foster skills, and enhance knowledge creatively. While teachers must inspire students to constantly inquire in their learning process, they are more and more seen as facilitators of test preparation and fact-based curriculum implementers. This issue is not only related to the problem of what is best for students. It is the question of democracy, too. Rees (2001) argues that he is entitled to academic freedom as an instructor at an educational institution.

\section{Case of Azerbaijan}

In the Soviet Union, the high school diploma was called the "Certificate of Maturity " (Attestat Zrelosti). The knowledge assessment was based on oral and written exams. The name of the diploma speaks for itself. The students were supposed to demonstrate more than just standard knowledge and prove that they were mature enough to step into graduate studies. The primary issue with this type of education was that the educational system was politicized, indoctrinated with Marxism, and thus not intended to bring up critical thinkers, as it did not serve the cause. Therefore, the Soviet schools did not foster dissent opinion.

After the collapse of the USSR in 1991, many countries adopted standardized knowledge assessment. Azerbaijan embarked upon reforms in education; trying to westernize the system had created many frustrations and positive changes. One of the major reforms was the implementation of standardized university admission testing. The positive consequence of this standardized testing was that it helped eliminate corruption for admission exams. Students had to pass standardized tests through the country-wide central testing commission, which did not depend on university admission.

Incrementally testing became one major tool for evaluating students' knowledge in all educational institutions, not only part of university admission. Comparing the evaluation system of the universities before adopting the standardized testing, one can notice that the old system considered a more individual approach. The teachers had a huge role in evaluating their students, thus knowing their needs and abilities. Moreover, the exams covered inclusive spectra of knowledge.

Testing became a mechanical system of evaluating knowledge. Giving the students the opportunity of multiple-choice has diminished the demand for creativity and a broader understanding of the subject because the students could sometimes guess 
the answers. Unfortunately, when teachers' jobs became preparing to pass the test successfully, their status diminished in the learning process.

In the initial period after the collapse of the Soviet Union, the evaluation system at the university was still based on the Soviet approach, i.e., the teachers examined the students themselves based on the specially prepared exam questions. Certain subjects even consisted of two types of exams: oral and written. In the end, the teacher was the authority to grade the students. Based on the student's overall performance and the exam results, the teachers marked them considering their knowledge and performance during the term. Thus, it gave freedom to teachers and valued the teachers' input during the term.

When the university introduced standardized testing for evaluating students after each term, the teachers lost the authority to evaluate the students' performance. Thus, teachers taught them during the whole term, and in the end, students took one standardized test based on multiple choices. Based on collective work, one test was prepared for the entire faculty relevant for every level. Teachers from different faculties proctored the testing procedure. Although this type of knowledge assessment eliminated corruption, it diminished the role of the teacher and creative approach in students' knowledge assessment. Another shortcoming of this type of standardized testing was that teachers had to prepare students for specific tests. Literacy became a matter of secondary importance, as the students had to prepare to pass a test based on textbooks. Enhancing students' knowledge became more challenging to achieve, especially because of the psychological pressure students endured in preparation and passing tests. Teachers' role was reduced to test preparation merely. While a teacher was supposed to increase the students' literacy, they had to care about bureaucracy. Chomsky and Robichaud (2014) argue that:

Standardized educational practices represent an attack on humanistic and critical education, as they are politically made to annihilate students and teacher's creativity, individuality, and autonomy to create more effective measures of uniformity and controls (p.1)

Changes in the educational system are still in progress, and even though universities and schools have introduced different types of knowledge assessment, tests are still part of it. For example, standardized tests are still applied for university entrance the same as in the West.

\section{Limitations}

This study solely relies on secondary data that was collected at different times from different countries. Therefore, there may be variability of the information and the present time. Also, the populations of various studies are small; therefore, it may be challenging to use the conclusions for the general students' population. Additionally, there is no generally accepted definition of students' learning and creativity and; therefore, creativity in this context has been defined as the ability of students to 
express their knowledge in a unique format; or diversely express their thoughts. Data analysis was challenging for the study because samples are different, and there are many variables involved. This study has used a theoretical approach, and there is a possibility that the results may vary if questionnaires and random sampling from the students' population were conducted. Therefore, there should be further studies on the impacts of standardized testing on students, the country's economy, and teachers for a particular country.

\section{Recommendations}

The government should incorporate multiple assessment methods such as oral tests, essay writing, designing prototypes while standardized tests are made the last assessment option. A study by Eminli (2019) notes that there is no perfect method of testing students' knowledge; therefore, using multiple forms of tests in a single assignment such as essays and multiple choices may be a relatively better way of assessing students' knowledge.

Students' knowledge should be assessed based on their critical thinking and creativity.

Tests should not be used as determinants of academic success and could be used to redefine the curriculum.

Redesigning the curriculum to promote inquiry-based learning could foster developing better knowledge assessment methods.

There should be no ranking of students based on the tests; instead, teachers should hold the scores as tools for strategizing to teach the students effectively.

\section{Conclusion}

Like the famous figure of Greek mythology, Procrustes, who was trying to fit people into standard beds by cutting the limbs or stretching them, the concept of standardized testing might follow the consequences of his approach. The educators need to promote an inquiry-based education process instead of memorization.

Education needs to change the attitude of treating students as a whole and not as an individual. Instead of enhancing literacy, the educational system is more concerned about fitting into the standards without considering the students' cultural and intellectual backgrounds and considering the students as individuals with unique abilities. Suppose the teachers were given a chance to evaluate students' knowledge based on their ability. In that case, it could have subdued many frustrations and brought more benefit to developing creativity, enhancing knowledge, and preparing them for the modern job market.

Trying to improve the educational system, Azerbaijan, like other countries, was trapped in standardized testing. It is an example when the countries trying to improve the system do not necessarily have to copy the West as the West has created its 
problems on the way of advancement. The positive outcome of the standardized test was that it eliminated the corruption for university admission in Azerbaijan.

In the modern world of innovations, the knowledge is constantly changing, and a skillful learner or employee needs to be able to find the "knowledge," to apply the "knowledge," and to change the "knowledge" if needed. Unfortunately, the standard knowledge assessment does not yet meet the requirement of this new concept.

\section{References}

[1] Abizada, A., \& Mirzaliyeva, F. (2019). Selection Criteria for the Honors Program in Azerbaijan.

[2] Altwerger, B., Strauss, S. L., Labbo, L. D., \& Bomer, R. (2002). The business behind testing. Language Arts, 79(3), 256.

[3] Berliner, D. (2009). MCLB (Much Curriculum Left Behind): A U.S. calamity in the making.

[4] Briggs, S. (2013). The Perils of Standardized Testing: 6 Ways It Harms Learning-Retrieved 8 September 2021, from https://www.opencolleges.edu.au/informed/features/the-perils-ofstandardized-testing/.

[5] Britannica, T. Editors of Encyclopaedia (2020, May 12). Chinese civil service. Encyclopedia Britannica.https://www.britannica.com/topic/Chinese-civilservice

[6] Carroll, J. M. (2013). The Brutal Reality of Bringing Kids up to Level: Are Critical Thinking and Creativity Lost in the World of Standardized Testing?.

[7] Chomsky, N. \& Robichaud, A. (2014). Standardized testing as an assault on Humanistic and Critical Education, Radical Pedagogy, 11(1). Retrieved on June 20, 2021, from https://www.academia.edu/20243378

[8] Eminli, H. (2019). The Need for Assessing Knowledge through Writing for the Quality of Education in Post-Soviet Middle-Low Income Countries with an Emphasis on Azerbaijani Context. International Education Studies, 12(3), 50-58.

[9] Frederick Taylor in the classroom: standardized testing and scientific management. Radical Pedagogy, (3), 2. Retrieved on June 15, 2021, from http://radicalpedagogy.icaap.org/content/issue3_2/rees.html

[10] Gardner, J. (Ed.). (2012). Assessment and learning. Sage.

[11] Jorgenson, 0. (2012). What We Lose in Winning the Test Score Race. Principal, 91(5), 12-15.

[12] McCarthy, C., \& Blake, S. (2017). Is This Going to Be on the Test? No Child Left Creative. SRATE Journal, 26(2), 25-31.

[13] Moon, T. R., Brighton, C. M., Jarvis, J. M., \& Hall, C. J. (2007). State Standardized Testing Programs: Their Effects on Teachers and Students. National Research Center on the Gifted and Talented. 
[14] Novinger, S. \& Compton-Lilly, C. (2005). Telling our stories: speaking truth to power. Language Arts, 82, pp. 195-203.Rees, J. (2001).

[15] Nusche, R. (2013). Student assessment: Putting the learner at the center. Synergies for Better Learning: An International Perspective on Evaluation, 133.

[16] Orfield, G. (2004). Dropouts in America: Confronting the Graduation Rate Crisis. Harvard Education Press. 8 Story Street First Floor, Cambridge, MA 02138.

[17] Phi Delta Kappa (PDK) (2015). The tipping point on testing? The 47th Annual Phi Delta Kappa/Gallup Poll of the Public's Attitudes toward the Public Schools. American Educator, 39(3)

[18] PISA. Dixiederivatives.com. Retrieved 8 September 2021, from http://dixiederivatives.com/Taleb/TheBedofProcrustes.pdf.

[19] Shively, K., Stith, K. M., \& Rubenstein, L. D. (2018). Measuring what matters: Assessing creativity, critical thinking, and the design process. Gifted Child Today, 41(3), 149-158.

[20] Shukakidze, B. (2013). Comparative Study: Impact of Family, School, and Students Factors on Students Achievements in Reading in Developed (Estonia) and Developing (Azerbaijan) Countries. International Education Studies, 6(7), 131-143.

[21] Smith, V. G., \& Szymanski, A. (2013). Critical thinking: More than test scores. International Journal of Educational Leadership Preparation, 8(2), 16-25.

[22] Spann, P., \& Kaufman, D. (2015). The negative effects of high-stakes testing. Education Law and Policy, 1(1), 1-14. 